\title{
SpyGlass Pancreatoscopy and Successful Retrieval of a Proximally Migrated Pancreatic Stent; Unusual Case and Technical Tips
}

\author{
Aliraza Rahimi ${ }^{1}$, Fardad Ejtehadi ${ }^{*}$
}

1. Therapeutic Endoscopy and Advanced ERCP Ward, Namazi Hospital, Gastroenterology and Hepatology Section, Internal Medicine Department, School of Medicine, Shiraz University of Medical Sciences, Shiraz, Iran

\footnotetext{
* Corresponding Author: Fardad Ejtehadi, MD

Therapeutic Endoscopy and Advanced ERCP Ward, Namazi Hospital, Namazi square, Zand Avenue, Shiraz, Iran Postal code: 71939-11351 Telefax: +98 7136473236 Email: edjtehadif@sums.ac.ir

Received: 07 Mar. 2016 Accepted: 01 Jun. 2016
}

\section{ABSTRACT}

Pancreatic stent proximal migration is a well known complication of pancreatic duct stenting, which occurs in about $5-6 \%$ of cases. Serious complications should be avoided by retrieval of the stent via different endoscopic techniques. We report a new technique previously reported only once (in a pancreatic duct with underlying pathology), to remove the proximally migrated pancreatic stent in a normal pancreatic duct by SpyGlass Direct Visualization System (Boston Scientific, Natick, Massachusetts, USA) and SpyBite Forceps (Boston Scientific, Natick, Massachusetts, USA)

KEYWORDS: Pancreatic stent; ERCP; Cholangioscopy

Please cite this paper as:

Rahimi AR , Ejtehadi F. SpyGlass Pancreatoscopy and Successful Retrieval of a Proximally Migrated Pancreatic Stent; Unusual Case and Technical Tips. Middle East J Dig Dis 2016;8:232-234. DOI :10.15171/mejdd.2016.26

\section{INTRODUCTION}

Pancreatic stent proximal migration is a well known complication of pancreatic duct stenting, which occurs in about $5-6 \%$ of cases. ${ }^{1}$ Risk factors for pancreatic stent migration are not well identified but stent placement for a long period and frequently exchanged stents should be done with more caution. ${ }^{2}$ Serious complications of a left in place migrated stent such as pancreatitis and pancreatic abscess ${ }^{1,3}$ should be avoided by retrieval of the stent via different endoscopic techniques including forceps and snare grasping, balloon extraction, basket grasping, and wire cannulation with insertion of another larger diameter stent over the migrated stent and removing both. ${ }^{4,5}$ Endoscopic retrieval techniques have a success rate of $87 \%{ }^{6}$

We report a new technique previously reported only once, to remove the proximally migrated pancreatic stent by SpyGlass Direct Visualization System (Boston Scientific, Natick, Massachusetts, USA) and SpyBite Forceps (Boston Scientific, Natick, Massachusetts, USA). ${ }^{7}$

\section{CASE REPORT}

A 65-year-old woman presented with common biliary duct stones, normal pancreatic duct, and no history of pancreatic disease. In the first endoscopic retrograde cholangiopancreatography (ERCP) with Model TJFQ180V Duodenoscopes (Olympus Co., Ltd., Tokyo, Japan), due to twice 


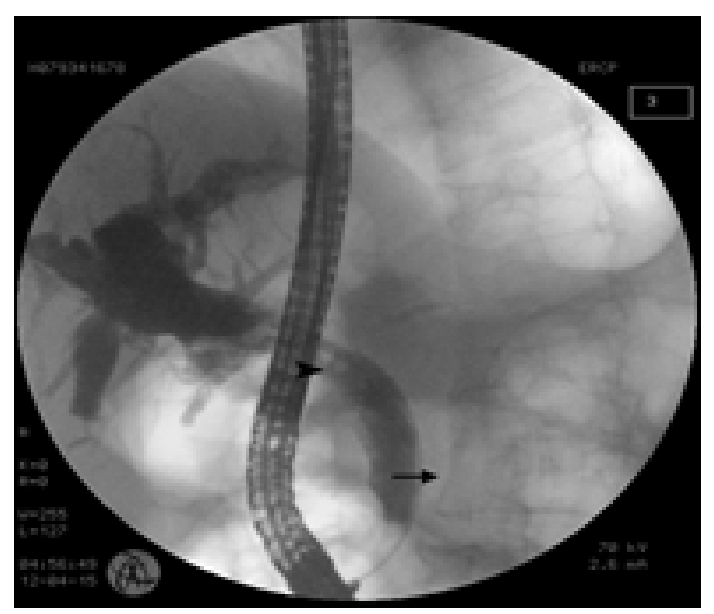

Fig.1: ERCP demonstrated the pancreatic duct stent (arrow) and common biliary duct stones (arrow head)

experiencing unwanted pancreatic duct guide wire cannulation, a 5-Fr, 7cm simple flanged Teflon-coated pancreatic stent (ENDO-FLEX GmbH, Germany) was inserted to minimize the risk of post procedure pancreatitis. The procedure was continued and the stones were retracted successfully (figure1). One week later in a second ERCP to remove the pancreatic stent, it was found that the stent had migrated deeply into the proximal part of the pancreatic duct. Several attempts to retrieve the stent by forceps, snare, and balloon extraction failed. So after insertion of $0.025 \mathrm{~mm}$ guide wire, SpyGlass cholangioscopy system (Boston Scientific, Natick, Massachusetts, USA) was used (figure 2). The SpyScope has the advantage of 4-way tip deflection steering system, which provides excellent facilitated maneuverability in the small ducts and we could visualize the distal end of the stent. The distal end of the stent was grasped by SpyBite forceps (Boston Scientific, Natick, Massachusetts, USA) and the stent was retrieved safely. The patient was admitted to hospital for 24 hours to closely be monitored for early signs of pancreatitis and then discharged. The duration of procedure was 3 hours. Initial attempts with snare, basket, and balloon took about 1.5 hours and 1.5 hours were spent on final attempts with SpyGlass Direct Visualization System.

\section{DISCUSSION:}

To our knowledge, there have only been 2 reports of the use of SpyGlass Cholangioscopy System to remove the

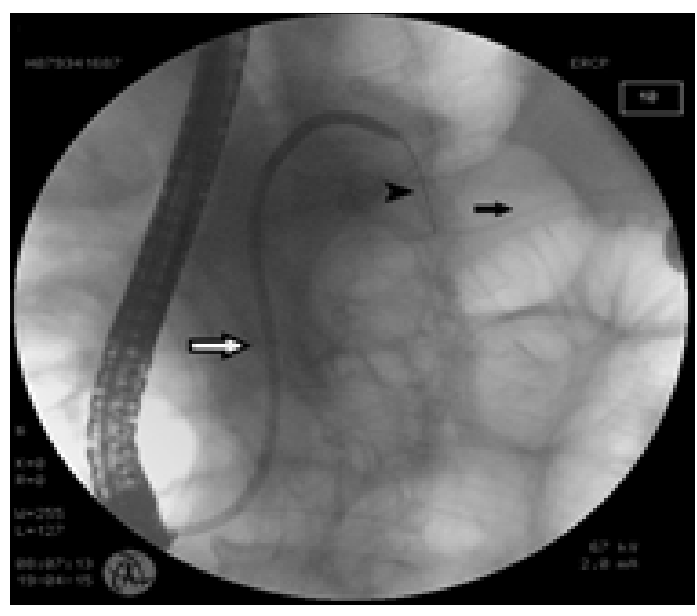

Fig.2: Spyscope (empty arrow) inserted in the pancreatic duct over the guide wire (arrow head) to the distal end of the deeply migrated pancreatic duct stent (arrow)

proximally migrated pancreatic stents. In the first case, the migrated stent was retrieved by SpyBite forceps ${ }^{7}$ and in the second case, the stent was retrieved by Soehendra Stent Retriever (Wilson-Cook, Winston-Salem, North Carolina, USA). ${ }^{1}$ In both cases the pancreatic duct or sphincter had underlying pathology and our report is the first case of successful retrieval of a migrated pancreatic stent in a normal pancreatic duct with SpyGlass Cholangioscopy system and SpyBite forceps.

\section{Technical Tips:}

1- We recommend using a guide wire deeply inserted in the proximal part of the pancreatic duct. This technique facilitates the insertion of other instruments such as snare and basket and decreases the risk of unwanted damage to the wall of the pancreatic duct. Also, an inserted guide wire could be useful for identification of pancreatic duct orifice and the course of pancreatic duct in the fluoroscopy.

2- About 2.5 liters of normal saline were used by irrigation pump (Boston Scientific, Natick, Massachusetts, USA) during the procedure. We think that using plenty of normal saline facilitates the visualization of pancreatic duct lumen, prevents the lateral damage to the pancreatic duct, and decreases the chance of pancreatitis.

3- The most challenging part of the procedure was to grasp the distal end of the stent by SpyBite forceps. This may be more difficult if the distal end of the stent settles just after any sharp angulation of pancreatic duct.

4- It is recommended that the stent be retrieved very 
gently if the grasping fails in the midway, as it may waste time and efforts.

SpyGlass Direct Visualization System is a single-operator system. But in difficult and critical cases it could be helpful if the device is detached from the ERCP scope body and another colleague is asked to control and maneuver the SpyGlass Direct Visualization System separately.

\section{CONFLICT OF INTEREST}

The author declares no conflict of interest related to this work.

\section{REFERENCES}

1. Maydeo A, Kwek A, Bhandari S, Bapat M, Mathew P. SpyGlass pancreatoscopy-guided cannulation and retrieval of a deeply migrated pancreatic duct stent. Endoscopy 2011;43 Suppl 2 UCTN:E137-8. doi: $10.1055 / \mathrm{s}-0030-1256205$.

2. Kawaguchi Y, Lin JC, Kawashima Y, Maruno A, Ito $\mathrm{H}$, Ogawa $\mathrm{M}$, et al. Risk factors for migration, fracture, and dislocation of pancreatic stents. Gastroenterol Res Pract 2015;2015:365457. doi: $10.1155 / 2015 / 365457$.

3. Matsumoto K, Katanuma A, Maguchi H. Endoscopic removal technique of migrated pancreatic plastic stents. J Hepatobiliary Pancreat Sci 2014;21:E3440. doi: 10.1002/jhbp.94.

4. Vila J, Marcos K, Manuel PM. Retrieval of Proximally Migrated Pancreatic Stents. Video Journal and Encyclopedia of GI Endoscopy. 2010;2:584-7.

5. $\mathrm{Lu} \mathrm{Y,} \mathrm{Jin} \mathrm{Z,} \mathrm{Wu} \mathrm{JC,} \mathrm{Bie} \mathrm{LK,} \mathrm{Gong} \mathrm{B.} \mathrm{Endoscopic}$ retrieval technique of proximally migrated pancreatic stents: a retrospective study in a tertiary centre. Gastroenterol Res Pract 2015;2015:485980. doi: $10.1155 / 2015 / 485980$.

6. Price LH, Brandabur JJ, Kozarek RA, Gluck M, Traverso WL, Irani S. Good stents gone bad: endoscopic treatment of proximally migrated pancreatic duct stents. Gastrointest Endosc 2009;70:174-9. doi: 10.1016/j.gie.2008.12.051.

7. Kantsevoy SV, Frolova EA, Thuluvath PJ. Successful removal of the proximally migrated pancreatic winged stent by using the SpyGlass visualization system. Gastrointest Endosc 2010;72:454-5. doi: 10.1016/j.gie.2009.11.029. 